\title{
A pragmatic assessment of the usefulness of the MODIS (Terra andAqua) 1-km active fire (MOD14A2 and MYD14A2) products for mapping fires in the fynbos biome
}

\author{
Helen de Klerk \\ Scientific Services, Western Cape Nature Conservation Board, Private Bag X5014, Stellenbosch 7599, South Africa. Email: \\ hdeklerk@capenature.co.za
}

Published in: International Journal of Wildland Fire 2008, 17, 166-178

\begin{abstract}
The moderate resolution imaging spectroradiometer (MODIS) fire-affected area data are not currently available for download by the public; therefore, 1-km pixel MODIS active fire data (MOD14A2 and MYD14A2) were assessed as a potential source of fire history data for the fynbos biome. These data mapped between 60.1 and $65.7 \%$ of the area within fire boundaries mapped by reserve managers between July 2002 and April 2005. These results should not be taken as a negative reflection on the MODIS team, as active fires do not aim to map fire-affected area. Rather this exercise has helped identify specific limitations in the fynbos, which will provide insight into the fine-tuning of other MODIS fire products for use in the fynbos. Limitations are likely to be primarily due to sun-glint around coastlines; topographic shadows; highly reflective, light soils exposed after a fire; partial burning of pixels; patchy and irregular-shaped fires; and large pixel size. The MODIS active fire data are not sufficient for the purposes of developing a 4-year fire history of the fynbos. The publication of the 500-m MODIS fire-affected area data is eagerly anticipated as a solution.
\end{abstract}

Keywords: burned areas, Cape Floristic Region, conservation management, fire-affected area, fire scars, GIS, remote sensing, South Africa, Western Cape.

\section{Introduction}

The Cape Floristic Region, commonly termed the 'fynbos', is one of the most species-rich floristic regions in the world (e.g. Cowling et al. 1992; Goldblatt and Manning 2002), and is identified as a Conservation International hotspot, containing the greatest non-tropical concentration of higher plant species in the world (Mittermeier et al. 2004), despite its small geographical extent. The management of protected areas, both formal and informal, in the fynbos is primarily the responsibility of a governmental (provincial) nature conservation agency, namely the Western Cape Nature Conservation Board (WCNCB). Fire is an integral part of the functioning of the fynbos ecosystem, and has played a significant role in the development of the patterns of botanical diversity in this region (Cowling 1987). Fynbos plants and animals have become adapted to periodic (mainly summer) fires, and have indeed become dependent on fire to complete their life cycles (e.g. Keeley and Bond 1997 and references therein). Fire is thus a key aspect for managers of fynbos areas to understand, so that they can make appropriate management decisions in this very important biodiversity hotspot (e.g. Richardson et al. 1994).

There are many aspects of a particular fire event, and of a series of fire events, that determine the post-fire plant community composition. These are broadly termedthe 'fire regime'(Gill 1975). One of the critical factors is the lapse of time between fires, typically termed the fire return interval (e.g. Vlok and Yeaton 2000). Too short a fire return interval does not allow non-sprouting floral elements of the community time to mature and produce seed (van Wilgen 1987), or the sprouting species to produce lignotubers and/or sufficiently thick bark to survive fires (e.g. Cowling 1987).Too long a fire return interval results in drop-off in seed production, and eventually in the death of adult plants. The seed of many non-sprouting fynbos plant species rapidly lose viability and are predated once released from cones, which may open with the death of the parent plants, or shortly thereafter (for a review see Le Maitre and Midgley 1992). Thus, as with too short a fire interval, too long a fire interval can result in localised extinction of species (Le Maitre and Midgley 1992).

Much has been written about appropriate fire return intervals in the fynbos, ranging from 10 to 50 years (e.g. Le Maitre and Midgley 1992; Richardson and van Wilgen 1992). The number of years after a fire required for non-sprouting proteas to become reproductively mature (i.e. the youth period, as described in Vlok and Yeaton 2000) of plant species will differ from each other, and for a species, with altitude and habitat (e.g. Le Maitre 1987). Consequently, the appropriate minimum and maximum fire intervals, or appropriate thresholds (see Rogers and Biggs 1999) for the fire 
interval, need to be measured for each reserve, and even for different climatic zones in a reserve, e.g. for northern and southern slopes (see de Klerk et al. 2007).

Once these fire interval thresholds have been determined, Reserve Managers will need to know the fire history of an area in order to evaluatewhether these thresholds have been exceeded by too short or too long fire intervals. This knowledge will help Reserve Managers to understand the impacts of the fire history on the plant communities (e.g. van Wilgen 1987; Keeley and Fotheringham 2001), and to determine future fire management actions.

Reserve Managers in the WCNCB must complete reports and maps for all fires that occur within the protected areas that they manage. For some protected areas, the fire history is comprehensive, going back to the early 1930s or 1940s, e.g. Swartberg Provincial Nature Reserve and CederbergWilderness Area. Other protected areas may have less complete fire history records. There are few fire history records for fynbos vegetation occurring outside of formal protected areas. As the WCNCB seeks to extend conservation initiatives into privately owned land, outside formally proclaimed protected areas, it becomes imperative to build up a fire history for these areas, so that the WCNCB can provide ecologically sound advice regarding fire management.

Remote sensing products have the potential to help the WCNCB to develop a complete fire history record for the whole fynbos biome, as has been advocated for the savanna and woodland parts of southern Africa (e.g. Trigg and Flasse 2001; Roy et al. 2005a, 2005b). Methods used to map fire-affected areas (also termed burned areas or fire scars) from various satellite sensors are based on a wide variety of approaches (e.g. see Pu et al. 2004 and Shabanov et al. 2005 for good reviews of available methods). However, few studies proposing particular methods for mapping fire-affected areas using remotely sensed data provide comparisons of their results with vetted fire boundaries (see Gitas et al. 2003; Li et al. 2003; Pu et al. 2004; Chuvieco et al. 2005; and Roy et al. 2005a for studies that do provide such comparisons). Consequently, it is difficult to conduct an evaluation of the different methods available. In addition, many fire-affected area mapping techniques require very expensive remote sensing software packages, experts to operate the software and much processing time, which are beyond the reach of cash-strapped governmental, para-statal, and non-governmental conservation agencies. Consequently the moderate resolution imaging spectroradiometer (MODIS) fire products provide much promise to such organisations. The MODIS/Terra and MODIS/Aqua 1-km thermal anomalies (MOD14A2 and MYD14A2) product provides 8-day summaries of active fires (henceforth referred to as 'MODIS active fires data or product'), free of charge, available for download in a variety of formats. Therefore, it has the potential to provide a remotely sensed fire history product within the financial and logistical constraints of the WCNCB. As the aim of the MODIS active fires product is to map active fires per se at the moment of satellite overpass, and not necessarily to map the entire fire-affected area (see Roy et al. 2005b), it is not the ideal product to use to develop a 4year fire history for the fynbos (Li et al. 2003; Pu et al. 2004; Roy et al. 2005b). However, the fire-affected area products that will be released for MODIS (e.g. Giglio 2005; Roy et al. 2005b) are not currently available. In addition, although goodwork has been conducted to test the products of fire-affected area algorithms in other regions in southern Africa dominated by grassland, savanna and open woodlands (e.g. Trigg and Flasse 2001; Roy et al. 2005a), the fireaffected area products have not been specifically tested in the fynbos region, in the south-western corner of South Africa. Fynbos differs from savanna, grassland and woodland systems in a number of aspects that are expected to impact reflectance values of pre- and post-burn vegetation (see Trigg and Flasse 2001), namely the dense nature of the pre-burn vegetation structure, the colour of the underlying soils exposed after the fire, and the heterogeneity of the distribution of soils, the amount and complexity of topographic shadows, and coastal glint.

The present paper sets out to evaluate the comprehensiveness of the MODIS active fires product for the development of a 4-year fire history for the fynbos biome. This exercise is not aimed at criticising the active fire or fire-affected area products, but rather it is aimed at evaluating where they are meeting the needs of conservation agencies in the fynbos, and where not. The latter is seen as a positive step towards highlighting technical aspects where these products might need to be tailored to the localised situation of the fynbos. Although the fynbos covers a small area within southern Africa, and so it may be considered unimportant to pursue high accuracy of fire products within this small area, it constitutes one of the six floral kingdoms of the world and a biodiversity hotspot (Goldblatt and Manning 2002; Mittermeier et al. 2004), which is fire-prone and fire-dependent (Cowling 1987; Keeley and Bond 1997), and thus the WCNCB proposes that it is worthwhile investigating the performance of these fire products in this specific situation, and suggesting aspects that may possibly need to be addressed in order to derive a customised fire product for use within the fynbos. 


\section{Study area}

Protected areas managed by the WCNCB, which all fall within the Western Cape Province of South Africa, were examined (Fig. 1a). These areas include Provincial Nature Reserves (International Union for the Conservation of Nature and Natural Resources, IUCN, category II), State Forests (also IUCN category II), and Wilderness Areas (IUCN category I) and as well as privately owned Mountain Catchment Areas (MCAs); the latter are jointly managed by WCNCB and private landowners (Fig. 1b).

Most of the protected areas that are managed by theWCNCB fall within the Cape Floristic Region (e.g. Goldblatt and Manning 2002), which is broadly akin to the Mediterranean shrubland ecosystems in other parts of the world, such as the Californian chaparral, the Mediterranean shrub and woodland, the Chilean matorral, and theAustralian kwongan (e.g.Keeley 1992; Versveld et al. 1992). The Cape Floristic Region, commonly termed the 'fynbos', stretches between 32 and $34{ }^{\circ} \mathrm{S}$ and 18 and $24^{\circ} \mathrm{E}$. The area encompasses an impressive altitudinal range, stretching from sea level to peaks of $2325 \mathrm{~m}$ above sea level (Klein Swartberg). The area is dominated by the Cape Folded Mountain Belt (Rutherford and Westfall 1986), around which an apron of 'coastal' lowlands lies to the west and south. Consequently, much of the study area is characterised by topographical complexity and high rock cover, which has numerous implications for the use of remotely sensed data, including accurate georeferencing of images, and the impact of deep shadows, sun-glint, etc., on radiometric accuracy of images. In addition, the majority of the area is covered by light, highly reflective soils. These include highly leached Table Mountain Sandstone soils, and granites of the mountainous areas and the windblown marine sands and limestone-based coastal plains (Deacon et al. 1992; Mucina and Rutherford 2006). The mountains also contain patches of black soils of organic-rich sands at high altitudes and localised seeps. Deep colluvial soils that accumulate at the bases of the mountains are of yellow to red soils, with higher clay content. The valleys between the mountains often consist of Bokkeveld shales and clays, ranging from light grey to yellow, as do the Malmesbury shales and clays of the renosterveld lowlands (Mucina and Rutherford 2006). This description highlights first the highly reflective nature of the soils underlying much of the vegetation of the fynbos, and second, the patchy distribution and varied reflectivity of other soils scattered between the dominating Table Mountain Sandstone.

Temperatures can range from winter minima of $-3.2^{\circ} \mathrm{C}$ to summer maxima of $47{ }^{\circ} \mathrm{C}$ (Deacon et al. 1992). Minimum and maximum mean daily temperatures range from 14 to $22{ }^{\circ} \mathrm{C}$ in May and June (winter) and from 21 to $31{ }^{\circ} \mathrm{C}$ in December and January (summer) (Deacon et al. 1992; see this reference also for a good review of current and past climate). The western areas of the Cape Floristic Region are characterised by strong winter rainfall, whereas the eastern areas experience a bimodal (spring and autumn) rainfall (Rutherford and Westfall 1986; Deacon et al. 1992). Mean annual rainfall ranges from $210 \mathrm{mmto}$ more than $3000 \mathrm{~mm}$, increasing with altitude and, in general, towards the east (Rutherford andWestfall 1986). Orographic clouds, usually associated with strong south-easterly winds, provide mist precipitation on higher mountains during the summer (Rutherford andWestfall 1986). Strong föhn-like winds, known locally as berg winds, are often accompanied by high temperatures and sudden drops in humidity, which result in severe fire hazards (van Wilgen 1984). Unsurprisingly, 'fire season' is linked to rainfall, wind and temperature patterns, and falls mainly between November and March (e.g. vanWilgen et al. 1992).

\section{Data and analyses}

\section{Manager-mapped fire boundaries}

The WCNCB requires all Reserve Managers to map the boundary of each and every fire that occurs (even partially) on land managed by the organisation (Erasmus 2005). For many of the protected areas, fire boundary data (and associated fire reports) are available back to the 1930s (e.g. Swartberg and Cederberg). The fire records are not this impressive for all protected areas. However, recent initiatives within the WCNCB have ensured complete fire histories for formally protected areas for the period July 2002 to April 2005. A central fire register for the WCNCB is compiled and maintained from input received from Reserve Managers, members of the police and the public, as well as through the use of remote sensing tools such as the 'active fires' available from the Web Fire Mapper (http://maps.geog.umd.edu/, accessed October 2005). A Geographical Information System (GIS) technician follows up on all fire records on the central fire register until fire boundaries and reports have been received from Reserve Managers. However, despite these efforts, two or three fire reports are known to be outstanding for this period, and this fact is borne in mind in the interpretation of results. The fires mapped by Reserve Managers between July 2002 and April 2005 range from 0.007 ha to 15615.5 ha, demonstrating that even small fires are mapped. Annually, the total area of fires mapped by Reserve Managers is large, ranging from 24143.4 ha (in 2005) to 49623.4 ha (2004). 
Manager-mapped fires are received in ArcView 3.3 shapefile format (ESRI, Redlands, CA, USA), andwere merged to produce a single manager-mapped fire layer for each year between 2002 (July to December) and 2005 (January to April).

\section{MODIS active fires data}

Methods for mapping fire scars, burn scars, or fire-affected areas (see Roy et al. 2005b) from remotely sensed imagery are many and varied (see Pu et al. 2004 for a good review), most of which can be applied to MODIS data. Methods are applied to single or multiple date imagery, and to single or multiple bands, and include: (i) image differencing, such as the subtraction of, or calculation of ratios between, pre- and post-fire images, or indices (e.g. normalised difference vegetation index (NDVI)) (e.g. Barbosa et al. 1999); (ii) image classification, including standard unsupervised algorithms, supervised algorithms, neural networks (e.g. Shabanov et al. 2005) and object-oriented classification techniques (e.g. Gitas et al. 2003), sometimes with preclassification segmentation of the image(s); (iii) active fire detection methods, through single- or multi-channel threshold algorithms or contextual algorithms (e.g. Giglio et al. 2003; for a review, see Li et al. 2001); and (iv) various hybrid techniques, which use a combination of various image differencing and active fire detection techniques (e.g. Kucera et al. 2003; Li et al. 2003; Sukhinin et al. 2004). Note that even though active fire mapping techniques do not primarily aim to map the total area affected by a fire, and are usually too conservative as satellite overpasses may be too infrequent to capture all areas burned ( $\mathrm{Li}$ et al. 2003; Pu et al. 2004; Roy et al. 2005b), they were the start of fire scar (fire-affected area) mapping methods (e.g. Li et al. 2000), and active fire data is evaluated here as no fire-affected area data were available to the author.

The definition of thresholds employed to differentiate between changes in spectral signals, which may indicate a fire, non-fire disturbances, or 'no-change', is a critical aspect of both active fire and fire-affected area mapping. Changes in spectral signals may be evaluated over a time series of images, or between 'potential fire' pixels and surrounding unburned pixels in a single image. Fixed threshold algorithms (single or multi-channel) are empirically defined, and computationally simple, but are only applicable at the local (to regional) scale, and during a short fire season (Pu et al. 2004 and references therein). Adaptive, or relative, thresholds are defined by the level of contrast between a pixel and its surrounding (neighbourhood of) pixels (e.g. Giglio et al. 2003; Roy et al. 2005b). In theory, adaptive thresholds should be more flexible and effective over a range of areas (e.g. Roy et al. 2005b for MODIS; Pu et al. 2004 for the National Oceanic and Atmospheric Administration (NOAA) advanced very high resolution radiometer (AVHRR)).

The MODIS sensors onboard the Terra (launched 1999) and Aqua (launched 2002) polar orbiting satellites, are run by NASA's Earth Observing System (EOS) program, and provide medium-resolution spatial coverage (i.e. 250 to 1000-m pixel size) of the entire surface of the Earth every 1 to 2 days. The MODIS Fire and Thermal Anomalies Product (MOD14A2 and MYD14A2) is clearly described by Giglio (2005). According to this reference, the MODIS Fire and Thermal Anomalies Product is produced by the 'version 4 contextual algorithm' by Giglio et al. (2003), which aims to map active fires. This algorithm iterates through several steps, which basically: (i) mask out non-fire pixels (particularly clouds and water); (ii) then look for potential fire pixels, which are identified as those with brightness temperatures in and between the $4-\mu \mathrm{m}$ and $11-\mu \mathrm{m}$ bands that are significantly higher than those of neighbouring or background pixels (where 'significantly higher' is defined by a series of relative thresholds); and finally (iii) check for false alarms, particularly due to sun-glint and inaccurate definition of background pixels near deserts or coastlines (of the sea or freshwater bodies) (Giglio et al. 2003; Li et al. 2003; Giglio 2005).

The 1-km resolution 8-day summaries of the MODIS fire and thermal anomalies product (MOD14A2 and MYD14A2, based on Terra and Aqua, day and night) (Collection 4, Giglio 2005) were downloaded from http://edcdaac.usgs.gov/datapool/ datatypes.asp and http://delenn.gsfc.nasa.gov/ims-bin/pub/ nph-ims.cgi/u31622 (accessed February 2007). Note that the MOD14A2 and MYD14A2 products aim to 'identify pixels in which one or more fires are actively burning at the time of the satellite overpass' (Giglio et al. 2003), and therefore these products are not equivalent to the MODIS 'fire-affected area' products (e.g. Roy et al. 2002, 2005a, 2005b), which have not yet been fully released for public download. The MOD14A2 and MYD14A2 products represent maps of the actively burning fires seen at the instant of the satellite overpass (which can be assumed as $\sim 1 \mathrm{~min}$ out of $24 \mathrm{~h}$ each day, C. Ichoku, pers. comm.). They cannot, therefore, be expected to map the full fire-affected area, but may contain useful information on fire activity and its spatial and temporal variability in the fynbos. Despite the limitations of the active fire data, and in the absence of other 'burnt area' data being currently freely available for download, the WCNCB decided to evaluate the potential of the MODIS active fires product as a means of developing a 4-year fire history for the fynbos. 
MODIS images were downloaded as 'hdf' format, converted first to 'img' format and then into ArcInfo GRID format using ERDAS Imagine (Leica Geosystems, Atlanta, GA, USA). In ArcView 3.3 (ESRI) fire classes, namely 8 (lowconfidence fire) and 9 (high-confidence fire) (see Giglio 2005; http://edcdaac.usgs.gov/modis/mod14a2v4.asp, accessed February 2007), were queried from the ArcInfo GRID data, and these were converted to shapefiles, which were merged to produce annual MODIS active fires data shapefiles for each year between 2002 (July to December) and 2005 (January to April).

\section{Comparison of MODIS fire scar data with manager-mapped fire boundaries}

Several comparisons are made in order to evaluate the usefulness of the MODIS active fires product to provide a 4-year history for the fynbos biome. Comparisons are made by 'intersecting'MODIS active fire shapefiles and managermapped fire shapefiles per year, followed by simple queries:

i. The area (number of hectares) of fires mapped by Reserve Managers that are also mapped by MODIS. This is the most important comparison, as it provides an indication of the comprehensiveness of the MODIS active fire data in terms of capturing both fire events, and of the area burned;

ii. The area of manager-mapped fires not mapped by MODIS active fire data;

iii. The area of MODIS active fire data not mapped by managers-mapped fires;

iv. The area of fires mapped by MODIS active fire data not mapped by Reserve Managers on land managed by the WCNCB, which is a subset of the result from (iii); and

$\mathrm{v}$. The total area of manager-mapped fires is calculated in order to provide a denominator for percentage calculations for (i) and (ii).

The following values are calculated for general interest, rather than for informative comparison:

vi. The total area of fires mapped by MODIS active fire data; and

vii. The total area of fires mapped by Reserve Managers or MODIS active fire data.

For the calculation of (iv) and (v), shapefiles for Provincial Nature Reserves, State Forests, Wilderness Areas, and MCAs were compiled ('unioned') to produce a single data layer. This was used to clip annual MODIS active fires shapefiles to the area managed by the WCNCB to allow direct comparison with Reserve Manager-mapped fire shapefiles per year. This comparison was used to identify what fires the MODIS active fires product may have picked up which were not mapped by Managers.

\section{Results and discussion}

Although the MODIS active fires product gives useful information on where and when many fires have occurred in the fynbos between July 2002 and April 2005, comparison between this product and manager-mapped fires, for areas managed by the WCNCB, showed various discrepancies. These vary from manager-mapped fires not being mapped at all, being partially mapped, to being 'over-mapped'by theMODISactive fires product. There are some examples of fires mapped by the MODIS active fires product in areas managed by the WCNCB that are not mapped by Reserve Managers. These various discrepancies are discussed in detail below, with comments on possible causes thereof.

\section{Manager-mapped fires missed by the MODIS active fires product}

Several the manager-mapped fires that were missed by the MODIS active fires product are small (e.g. 282.5-ha fire in Matroosberg MCA burned between 18 and 20 January 2005, Fig. 2a). This is not surprising as a fire of this size could be as little as two or three pixels in the MODIS images (as there are 100 ha in a MODIS 1-km pixel). However, omissions can be quite large (e.g. 980 ha burned on 1 January 2003, also in the Matroosberg MCA, Fig. 2b). The latter fire, which burned for only 1 day,may have been missed owing to the limited number of overpasses of the sensors during this short period. These omissions in the MODIS active fires product are of serious concern as it is important that all fires (particularly those larger than $10 \mathrm{ha}$ ) are captured so that they contribute to calculations of fire interval (the number of years that have lapsed between successive fires). Fire interval will tell us whether the vegetation has had sufficient time to become reproductively mature and produce seed between fires (e.g. Vlok and Yeaton 2000). If the 
MODIS active fires product misses fires, analyses of fire interval may look more optimistic than the situation on the ground truly is. For instance, if the MODIS active fires product misses a fire, a piece of vegetation that is only 5 years old (i.e. reproductively immature) may appear to be 20 years old (i.e. reproductively mature).

Some 'missed' fires may be due to the topography of the land on which the fire occurred. For example, the 18-20 January 2005 Matroosberg MCA fire (Fig. 2a), which was not mapped by either the MODIS active fires product (Terra or Aqua) or the MODIS hotspots data on the Web Fire Mapper, is described by the Reserve Manager who mapped the fire as having burned on a ridge between two deep valleys. The fire maywell have been hidden from the satellite in one of the deep valleys for much of the time it burned. In addition, strong shadows may have reduced the ability of the MODIS sensor to detect the fire.Topographic shadows were noted by Roy et al. (2005a) to also reduce the accuracy and comprehensiveness of the fire-affected area product in those parts of their pilot area that are more mountainous, such as the Chimaliro Forest Reserve in Malawi and the Mecuburi Forest Reserve in Mozambique. Topographic shadows are likely to be a particular problem in application of the fire-affected algorithm to MODIS data in the fynbos, which is dominated by numerous, topographically complex mountain chains.

Although some small fires may be missed purely owing to their size, many other small manager-mapped fires are in fact mapped by the MODIS active fires product. A 399.2-ha fire in March 2005 in Walkerbay (Fig. 3a) was missed. However, a similar-sized fire just to the north of Walkerbay, which occurred a month earlier at Babilonstoring (426.6ha fire, February 2005, Fig. 3a), was mapped by the MODIS active fires product. Another two examples of small fires that were captured by the MODIS active fires product in 2005 occurred to the north of Hottentots-Holland (499.1 ha and 343.5 ha in Fig. 3b), and in fact these were 'over-mapped'. The Walkerbay fire missed by the MODIS active fires product occurred in a flat area, whereas the Hottentots-Holland and Babilonstoring fires, which were mapped by the MODIS active fires product, all occurred in mountainous areas. These results seem counter-intuitive, as one would expect satellites to be able to pick up thermal signals, and changes in signals, more easily in flat, topographically homogeneous areas, such as Walkerbay. However, Giglio et al. (2003) found that the identification of suitable background pixels in coastal areas was problematic in the 'version 4 contextual algorithm' (Giglio et al. 2003), which algorithm was employed to create the 'MODIS active fires Collection 4' dataset used in the present study.

TheWalkerbay Nature Reserve is bounded by a large river mouth to the north and by the sea to the west, and so $50 \%$ of its boundary constitutes coastline. This maywell have led to the inability of the MODIS active fires algorithm to detect the March 2005 fire in Walkerbay. According to Giglio (2005), the next iteration of the active fire algorithm, and associated MODIS active fires 'Collection', will aim to improve on this current shortcoming. Hopefully this solution can also be employed in the fire-affected area algorithm, which was found to be influenced by spectral confusion along the dryland-wetland interfaces of the Okovango swamp in Botswana (Roy et al. 2005a).

\section{Manager-mapped fires partially mapped by the MODIS active fires product}

Many manager-mapped fires are mapped by the MODIS active fires product, but only partially. In March 2005, there were three fairly large fires in theWestern Cape that clearly show the large mismatches between fire boundaries mapped by Reserve Managers and areas mapped by the MODIS active fires product, namely a 2109.4-ha fire in HottentotsHolland (Fig. 3c), a 1627.2-ha fire in the southern Groot Winterhoek (Fig. 3d), and a 7070-ha fire in the southern Cederberg (Fig. 3e). Although some of the fires were reportedly patchy, such as the fire in the Cederberg (Fig. 3e), which may result in discrepancies between manager-mapped boundaries and those mapped by the MODIS active fires product, this will not explain all discrepancies. However, the MODIS active fires product only aims to map fires that are actively burning at the time of satellite overpass and the overpass time of the satellite, which can be assumed to be $\sim 1$ min out of $24 \mathrm{~h}$ each day (C. Ichoku, pers. comm.) is very short, giving a very short temporal snapshot of an entire fire (Pu et al. 2004; Roy et al. 2005b). Potentially a fire can move more than one pixel between overpasses (which are typically 6 hours apart) and so gaps can appear in the fire scar mapped by the active fires, even if these gaps did actually burn (e.g. Li et al. 2003). Partial mapping of fires by the MODIS active fires product may also be due to partially burned pixels and irregular-shaped fire scars (e.g. Pu et al. 2004; Roy et al. 2005a), as well as clouds and smoke (e.g. Li et al. 2003).

The overall result of manager-mapped fires 'missed' or 'under-mapped' by the MODIS active fires product is that the MODIS active fires product mapped 60.1 to $65.7 \%$ of the area of fires mapped by Reserve Managers annually between July 2002 and April 2005 (Table 1). Uncertainty of the absolute accuracy of manager-mapped fires aside, a match that is only around twothirds is of concern, given the necessity to fully map all fires in order to accurately determine fire 
return interval at any given site. Although the ability to map two-thirds of manager-mapped fires may be a good reflection on the MODIS active fire product, which does not aim to map the total fire-affected area, it is not sufficient for deriving an accurate fire history record required to guide conservation management on the ground. This highlights the importance of thework being done to finalise the fire-affected MODIS products, and makes it clear that the teams working on finalising and implementing the fire-affected MODIS product require sufficient support.

\section{MODIS active fires in areas managed by the WCNCB not mapped by Reserve Managers}

The number of hectares of MODIS active fires in areas managed by the WCNCB not mapped by Reserve Managers (Table 1) needs to be interpreted with caution. Most discrepancies result from disagreement in placement of fire boundaries, rather than fires not being mapped by Reserve Managers at all (e.g. 'overmapping' of Babilonstoring fire in Fig. 3a). However, there are a fewexamples of fires mapped by the MODIS active fires product within Provincial Nature Reserves that have not been mapped by Reserve Managers, such as fires in Grootvadersbosch (Tygerberg, Paardeberg, and Spioenkop) in December 2003 (all shown in Fig. 4a).Afire in Ruitersbos-Doringrivier that burned between 17 and 24 November 2003 (Fig. 4b) has been confirmed by the Reserve Manager to have been mapped, but not submitted to the GIS technician. In such a case, the MODIS active fires product provides a tool for checking up on why no fire reports, with associated maps, have been submitted.The number of such cases, however, was very low.

More frequently, fires that are mapped by the MODIS active fires product in areas managed by the WCNCB for which there are no manager-mapped records have burned only in privately owned MCAs.Although Reserve Managers are supposed to map all fires occurring in MCAs, this is not always achievable, owing to the very high area-to-personnel ratios in these extensive areas. Consequently, not all fires in MCAs are mapped. In these cases, the MODIS active fires product could provide useful information on the approximate date and a very rough indication of the general location of fires that have not been mapped by Reserve Managers, although the discussion above shows that the MODIS active fires data will probably not map the fire-affected area with a high degree of accuracy.

\section{Problems with thresholds}

Changes in thresholds used in the algorithms to map active fires or fire-affected areas may lead to omissions or commissions in the resultant fire scar product (Roy et al. 2005b). It may be difficult, or impossible, to find a single suitable threshold, even for adaptive or relative thresholds, for application at the global scale (Csiszar et al. 2003; Li et al. 2003). This may impact the results of the MODIS active fires product despite efforts to reduce the sensitivity of results to thresholds, such as those implemented by Giglio et al. (2003). These difficulties in identifying suitable global thresholds may also have contributed to the insufficient performance of the MODIS active fires product within the localised situation of the fynbos biome, with its high levels of topographical relief and shadows, and inherently light soils.

\section{Can MODIS active fires product be used to map fires outside of areas managed by the WCNCB?}

As Reserve Managers are not obliged to map fires that occur on land not managed by the WCNCB, little can be said as to whether the MODIS active fires product can accurately map fires in areas not managed by the WCNCB. However, mismatches of manager-mapped fires and the MODIS active fires product in areas managed by the WCNCB, particularly in cases where the MODISactive fires product completely misses manager-mapped fires, show that the active fire product is not ideal. It would be useful to obtain MODIS fire-affected area data, developed with the use of the improved algorithm published by Roy et al. (2005b) and applied at a 500-m scale, in order to further evaluate the potential for the application of MODIS fire scar data for developing a fire history for the fynbos biome.

\section{Factors potentially impacting the performance of existing fire products in the fynbos}

Although good work has been conducted to test the products of fire-affected area algorithms in regions in southern Africa dominated by grassland, savanna and openwoodlands (e.g.Trigg and Flasse 2001; Roy et al. 2005a), the fireaffected area products have not been specifically tested in the fynbos region in the south-western corner of South 
Africa. Fynbos differs from savanna, grassland andwoodland systems in a number of aspects that are expected to impact reflectance values of pre- and postfire vegetation. Currently the fire-affected area algorithm relies on the post-fire colour of a fire-affected area to be darker than the pre-fire colour of the vegetation (Roy et al. 2005a). However, the dense nature of the vegetation structure in the fynbos first yields a dark pre-fire vegetation colour, and second provides a high fuel load,which often leads to awhite post-fire ash residue. Roy et al. (2005a) comment that the post-fire ash residue in their savanna pilot areas is typically dark. The predominantly light colour of the soils underlying the pre-fire vegetation in the fynbos will also add to the highly reflective nature of the post-fire surface, which is very different to the highly absorptive post-fire surface observed in the savannas. Additionally, the heterogeneity of the distribution of soils in the fynbos is likely to confound thresholds used to differentiate post-fire pixels from surrounding unburned pixels.

Dryland-wetland interfaces have been found to cause problems with the fire-affected area algorithm in Botswana (Roy et al. 2005a), as has sun-glint along coastlines for the active fire algorithm (Giglio et al. 2003).These problems of highcontrast edges are likely to be pertinent in the fynbos biome, which occurs at the south-western tip of the African continent and has a high coastline-to-land ratio.

Finally the fynbos is known for its majestic mountains, and these numerous and topographically complex mountains, which are in part responsible for the high levels of speciation and endemism in this floral kingdom (e.g. Cowling et al. 1992; Goldblatt and Manning 2002), will result in many topographic shadows, which are problematic to all fire products algorithms (e.g. Roy et al. 2005a). This topographical complexity may also impact the scale at which data should be analysed and generated.

\section{Conclusions}

The MODIS/Maryland team must be lauded for their efforts and the production of the MODIS active fires product, which is freely available for download in an easy-to-use format from the worldwideweb. However, it is probably not sufficient for the purposes of developing a 4-year fire history of the fynbos biome, and thus of impacting conservation management on the ground. The chief limitations would seem to be the impact of glint around coastlines (e.g. Walkerbay fire in Fig. 4a, Giglio et al. 2003; Li et al. 2003); high-contrast edges (Roy et al. 2005a); strong topographic shadows (e.g. Matroosberg fire in Fig. 3a, Roy et al. 2005a); highly reflective, light soils exposed after a fire; partial burning of pixels; patchy and irregular-shaped fires (Pu et al. 2004; Roy et al. 2005a, 2005b); short overpass time of the satellites (even for MODIS, which is much more frequent than for NOAA/AVHRR; C. Ichoku, pers. comm.); and interference of clouds and smoke (e.g. Li et al. 2003), and large pixel size.

All of these factors, except the short overpass time, are likely to also impact the utility of the fire-affected area product in the fynbos. However, the publication of 500-m MODIS fire-affected area data developed from the Roy et al. (2005b) algorithm on a website, from where they can be freely downloaded, is eagerly anticipated as a solution to many of theses challenges. Once tested and tailored to the specific conditions of the fynbos biome, the 500-m MODIS fireaffected area data holds much promise for the development of an accurate fire history for the fynbos.

\section{Acknowledgements}

My most sincere thanks to Charles Ichoku for contributing his valuable time tomy development in this field, and very useful comment on this manuscript. Mythanks also to Nadia Smith and three anonymous reviewers for comments on the contents of this manuscript, to Guy Palmer and Therese Forsyth for editorial input, and to Granville van Ross for extracting the manager-mapped fire boundaries from the WCNCB fire database.

\section{References}

Barbosa PM, Gregoire J-M, Pereira JMC (1999) An algorithm for extracting burned areas from time series ofAVHRRGACdata applied at continental scale. Remote Sensing of Environment 69, 253-263. doi:10.1016/S0034-4257(99)00026-7

Chuvieco EM, Ventura G, Martin PM, Gomez I (2005) Assessment of multitemporal compositing techniques of MODIS and AVHRR images for burned land mapping. Remote Sensing of Environment 94, 450-462. doi:10.1016/J.RSE.2004.11.006

Cowling RM (1987) Fire and its role in coexistence and speciation in Gondwanan shrublands. South African Journal of Science 83, 106-112. 
Cowling RM, Holmes PM, RebeloAG (1992) Plant diversity and endemism. In 'The Ecology of Fynbos: Nutrients, Fire and Diversity'. (Ed. RM Cowling) pp. 62-112. (Oxford University Press: Cape Town)

Csiszar I, Abuelgasim A, Li Z, Jin J, Fraser R, HaoW-M (2003) Interannual changes of active fire detectability in North America from long-term records of the advanced very high resolution radiometer. Journal of Geophysical Research 108(D2), 4075. doi:10.1029/2001JD001373

de Klerk H, Schutte-VlokA,Vlok J, ShawK, Palmer G, Martens C,Viljoen P, Marshall T, PurvesA, van Ross G, Forsyth T,Wessels N, Geldenhuys D, Wolfaardt A, Kirkwood D (2007) 'Ecological Fire Monitoring Manual.' Western Cape Nature Conservation Boards, Scientific Services, Internal Report.

Deacon HJ, Jury MR, Ellis F (1992) Selective regime and time. In 'The ecology of Fynbos: Nutrients, Fire and Diversity'. (Ed. RM Cowling) pp. 6-22. (Oxford University Press: Cape Town)

Erasmus Z (2005) 'Fire Management Policy Guidelines (for the Western Cape Nature Conservation Board)Version 3, September 2005.'WCNCB, Internal Report. (Cape Town)

Gill AM (1975) Fire and the Australian flora: a review. Australian Forestry 38, 4-25.

Giglio L (2005) 'MODIS Collection 4 Active Fire Product Users Guide,Version 2.2, 16 November 2005.' (Science Systems and Applications, Inc.) Available at http://modis-fire.umd.edu/documents/MODIS Fire Users Guide_2.2.pdf [Verified 20 February 2008]

Giglio L, Descloitres J, JusticeCO, KaufmanYJ (2003) An enhanced contextual fire detection algorithm for MODIS. Remote Sensing of Environment 87, 273-282. doi:10.1016/S0034-4257(03)00184-6

Gitas IZ, Mitri GH, Chuvieco E, Ventura G (2003) Object-oriented image analysis for burned area mapping using NOAA-AVHRR imagery in Creus Cape, Spain. In 'Proceedings of the 4th International Workshop on Remote Sensing and GIS applications to Forest Fire Management: Innovative Concepts and Methods in Fire Danger Estimation'. 5-7 June 2003, Ghent University, Ghent, Belgium. (Eds E Chuvieco, P Martin, C Justice) pp. 170-174. (EARSeL, Ghent University: Ghent, Belgium)

Goldblatt P, Manning JC (2002) Plant diversity of the Cape Region of southern Africa. Annals of the Missouri Botanical Garden 89, 281-302. doi:10.2307/3298566

Keeley JE (1992) A Californian's viewof fynbos. In 'The Ecology of Fynbos: Nutrients, Fire and Diversity'. (Ed. RM Cowling) pp. 372-388. (Oxford University Press: Cape Town)

Keeley JE, Bond WJ (1997) Convergent seed germination in South African fynbos and Californian chaparral. Plant Ecology 133, 153-167. doi:10.1023/A:1009748603202

Keeley JE, Fotheringham CJ (2001) Historic fire regime in Southern California shrublands. Conservation Biology 15, 1536-1548. doi:10.1046/J.1523-1739.2001.00097.X

Kucera J,YasuokaY, Dye DG (2003) Creating a forest fire database for the far east of Asia using NOAA/AVHRR observation. In 'Proceedings of the 4th International Workshop on Remote Sensing and GIS applications to Forest Fire Management: Innovative Concepts and Methods in Fire Danger Estimation'. 5-7 June 2003, Ghent University, Ghent, Belgium. (Eds E Chuvieco, P Martin, C Justice) pp. 175-177. (EARSeL, Ghent University: Ghent, Belgium)

Le Maitre DC (1987) Dynamics of canopy-stored seed in relation to fire. In 'Disturbance and the Dynamics of Fynbos Biome Communities'. South African National Scientific Programmes, Report No. 135. (Eds RM Cowling, DC Le Maitre, B McKenzie, RP Prys-Jones, BW van Wilgen) pp. 24-45. (CSIR, Foundation for Research Development: Pretoria)

Le Maitre DC, Midgley JJ (1992) Plant reproductive ecology. In 'The Ecology of Fynbos: Nutrients, Fire and Diversity’. (Ed. RM Cowling) pp. 135-174. (Oxford University Press: Cape Town)

Li Z, Nadon S, Cihlar J, Stocks B (2000) Satellite-based mapping of Canadian boreal forest fires: evaluation and comparison of algorithms. International Journal of Remote Sensing 21, 3071-3082. doi:10.1080/01431160050144965

Li Z, Kaufman YJ, Ichoku C, Fraser R, Trishchenke A, Giglio L, Jin J, Yu X (2001) A Review of AVHRR-based active fire detection algorithms: principles, limitations, and recommendations. In 'Global and Regional Vegetation Fire Monitoring from Space, Planning a Coordinated International Effort’. (Eds FJ Ahern, JG Goldammer, CO Justice) pp. 199-225. (SPB Academic Publishing: The Hague, the Netherlands)

Li Z, Fraser R, Jin J, Abuelgasim AA, Csiszar I, Gong P, Pu R, Hao W (2003) Evaluation of algorithms for fire detection and mapping across North America from satellite. Journal of Geophysical Research 108, 1-12.

Mittermeier RA, Robles GP, Hoffmann M, Pilgrim J, Brooks T, Mittermeier CG, Lamoreux J, da Fonseca GAB (2004) 'Hotspots Revisited: Earth's Biologically Richest and most Endangered Terrestrial Ecoregions.' (CEMEX: Mexico City)

Mucina L, Rutherford MC (Eds) (2006) 'The Vegetation of South Africa, Lesotho and Swaziland.' Strelitzia, Vol. 19. (South African National Biodiversity Institute: Pretoria)

Pu R, Gong P, Li Z, Scarborough J (2004) A dynamic algorithm for wildfire mapping with NOAA/AVHRR data. International Journal of Wildland Fire 13, 275-285. doi:10.1071/WF03054

Richardson DM, vanWilgen BW(1992) Ecosystem, community and species response to fire in mountain fynbos: conclusions from the Swartboskloof experiment. In 'Fire in South African Mountain Fynbos: Ecosystem Community and Species Response at Swartboskloof. Ecological Studies. Vol. 93'. (Eds BW vanWilgen, DM Richardson, FJ Kruger, HJ Van Hensbergen) pp. 273-284. (Springer-Verlag: Heidelberg) 
Richardson DM, van Wilgen BW, Le Maitre DC, Higgins KB, Forsyth GG (1994) A computer-based system for fire management in the mountains of the Cape Province, South Africa. International Journal of Wildland Fire 4, 17-32. doi:10.1071/WF9940017

Rogers K, Biggs H (1999) Integrating indicators, endpoints and value systems in strategic management of the rivers of the Kruger National Park. Freshwater Biology 41, 439-451. doi:10.1046/J.1365-2427.1999.00441.X

Roy DP, Lewis PE, Justice CO (2002) Burned area mapping using multitemporal moderate spatial resolution data - a bi-directional reflectance model-based expectation approach. Remote Sensing of Environment 83, 263-286. doi:10.1016/S0034-4257(02)00077-9

Roy D, Frost P, Justice C, Landmann T, Le Roux J, Gumbo K, Makungwa S, Dunham K, Du Toit R, Mhwandagara K, Zacarias A, Tacheba B, Dube O, Pereira J, Mushove P, Morisette J, Santhana Vannan S, Davies D (2005a) The Southern Africa Fire Network (SAFNet) regional burned area product validation protocol. International Journal of Remote Sensing 26, 4265-4292. doi:10.1080/01431160500113096

Roy DP, Jin Y, Lewis PE, Justice CO (2005b) Prototyping a global algorithm for the systematic fire-affected area mapping using MODIS time series data. Remote Sensing of Environment 97, 137-162. doi:10.1016/J.RSE.2005.04.007

Rutherford MC, Westfall RH (1986) The biomes of southern Africa - an objective categorization. Memoirs of the Botanical Survey of SouthAfrica 54, 50-53.

Shabanov NV, Lo K, Gopal S, Myneni RB (2005) Subpixel burn detection in Moderate Resolution Imaging Spectroradiometer 500-m data with ARTMAP neural networks. Journal of Geophysical Research 110, D03111. doi:10.1029/2004JD005257

Sukhinin AI, French NHF, Kasischke ES, Hewson JH, Soja AJ, Csiszar IA, Hyer EJ, LobodaT, Conard SG, RomaskoVI, Pavlichenko EA, Miskiv SI, Slinkina OA (2004) AVHRR-based mapping of fires in Russia: newproducts for fire management and carbon cycle studies. Remote Sensing of Environment 93, 546-564. doi:10.1016/J.RSE.2004.08.011

Trigg S, Flasse S (2001) An evaluation of different bispectral spaces for discriminating burned shrub-savannah. International Journal of Remote Sensing 22, 2641-2647. doi:10.1080/01431160110053185

van Wilgen BW (1984) Fire climates in the southern and western Cape Province and their potential use in fire control and management. South African Journal of Science 80, 358-362.

van Wilgen BW (1987) Fire regimes in the fynbos biome. In 'Disturbance and the Dynamics of Fynbos Biome Communities’. South African National Scientific Programmes, Report No. 135. (Eds RM Cowling, DC Le Maitre, B McKenzie, RP Prys-Jones, BW vanWilgen) pp. 6-14. (CSIR, Foundation for Research Development: Pretoria)

van Wilgen BW, Bond WJ, Richardson DM (1992) Ecosystem Management. In 'The Ecology of Fynbos: Nutrients, Fire and Diversity'. (Ed. RM Cowling) pp. 345-371. (Oxford University Press: Cape Town)

Versveld DB, Richardson DM, van Wilgen BW, Chapman RA, Forsyth GG (1992) The climate of Swartboskloof. In 'Fire in South African Mountain Fynbos: Ecosystem Community and Species Response at Swartboskloof. Ecological Studies. Vol. 93'. (Eds BW van Wilgen, DM Richardson, FJ Kruger, HJ Van Hensbergen) pp. 2136. (Springer-Verlag: Heidelberg)

Vlok JHJ, Yeaton RI (2000) The effect of short fire cycles on the basal cover and density of understorey sprouting species in South African mountain fynbos. Diversity \& Distributions 6, 233-242. doi:10.1046/J.14724642.2000.00087.X 
Table 1. Comparison of the area of manager-mapped fires against the area of moderate resolution imaging spectroradiometer (MODIS) active fire data

Comparisons are provided per year. Areas are in hectares, and the percentages (italicised) are of total areas of manager-mapped fires in that year

\begin{tabular}{|c|c|c|c|c|c|c|c|c|}
\hline \multirow[b]{2}{*}{ Comparison } & \multicolumn{2}{|c|}{2005 (January to April) } & \multicolumn{2}{|l|}{2004} & \multicolumn{2}{|l|}{2003} & \multicolumn{2}{|l|}{$\begin{array}{l}2002 \text { (July to } \\
\text { December) }\end{array}$} \\
\hline & $\mathrm{Ha}$ & $\%$ & $\mathrm{Ha}$ & $\%$ & $\mathrm{Ha}$ & $\%$ & $\mathrm{Ha}$ & $\%$ \\
\hline $\begin{array}{l}\text { Area of fires mapped by Managers also mapped } \\
\text { by MODIS }\end{array}$ & 15861.2 & 65.7 & 29847.4 & 60.1 & 29554.6 & 63.8 & 22848.8 & 65.0 \\
\hline $\begin{array}{l}\text { Area of fires mapped by Managers not mapped } \\
\text { by MODIS }\end{array}$ & 8282.2 & 34.3 & 19775.9 & 39.9 & 16776.8 & 36.2 & 12323.7 & 35.0 \\
\hline $\begin{array}{l}\text { Area of fires mapped by MODIS not map by } \\
\text { Managers }\end{array}$ & 162496.2 & - & 355741.5 & - & 530278.7 & - & 169202.4 & - \\
\hline $\begin{array}{l}\text { Area of fires mapped by MODIS not map by } \\
\text { Managers on land managed by CNC }\end{array}$ & 15568.5 & & 56398.2 & & 47081.6 & & 46920.7 & \\
\hline Total area of fires mapped by Managers & 24143.4 & - & 49623.4 & - & 46331.4 & - & 35172.6 & - \\
\hline Total area of fires mapped by MODIS & 178357.4 & - & 385588.9 & - & 559833.3 & - & 192051.3 & - \\
\hline $\begin{array}{l}\text { Total area of fires mapped by Managers and / or } \\
\text { MODIS }\end{array}$ & 186639.6 & - & 405364.9 & - & 576610.1 & - & 204375.0 & - \\
\hline
\end{tabular}


(a)

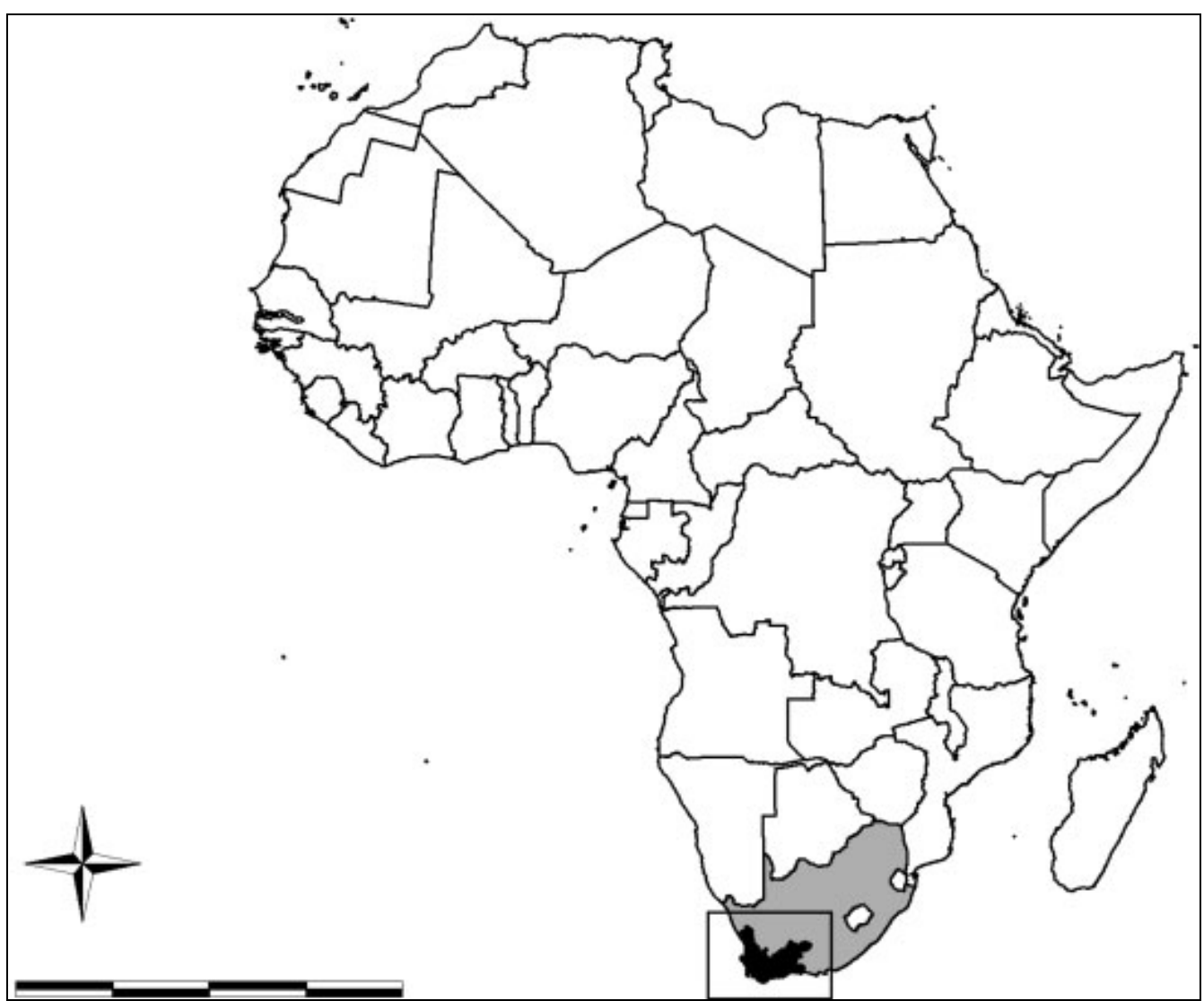

(b)

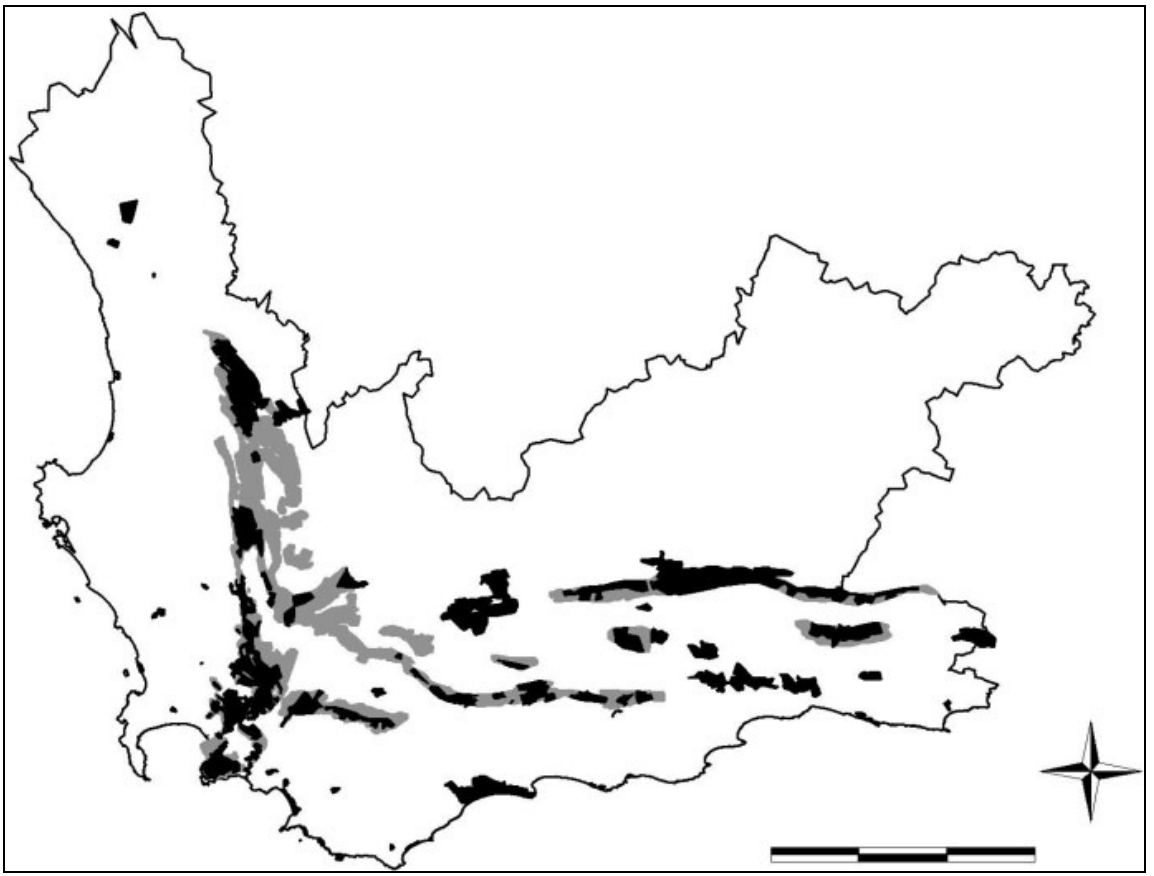

Fig. 1. (a) Location of theWestern Cape Province (solid black), within South Africa (solid grey). (b)An enlargement of theWestern Cape Province showing land managed for conservation purposes by theWestern Cape Nature Conservation Board, which includes statutory Provincial Nature Reserves (International Union for the Conservation of Nature and Natural Resources, IUCN, category II), State Forests (also IUCN category II), andWilderness Areas (IUCN category I) (solid black), and as well as privately owned, proclaimed Mountain Catchment Areas (solid grey). 

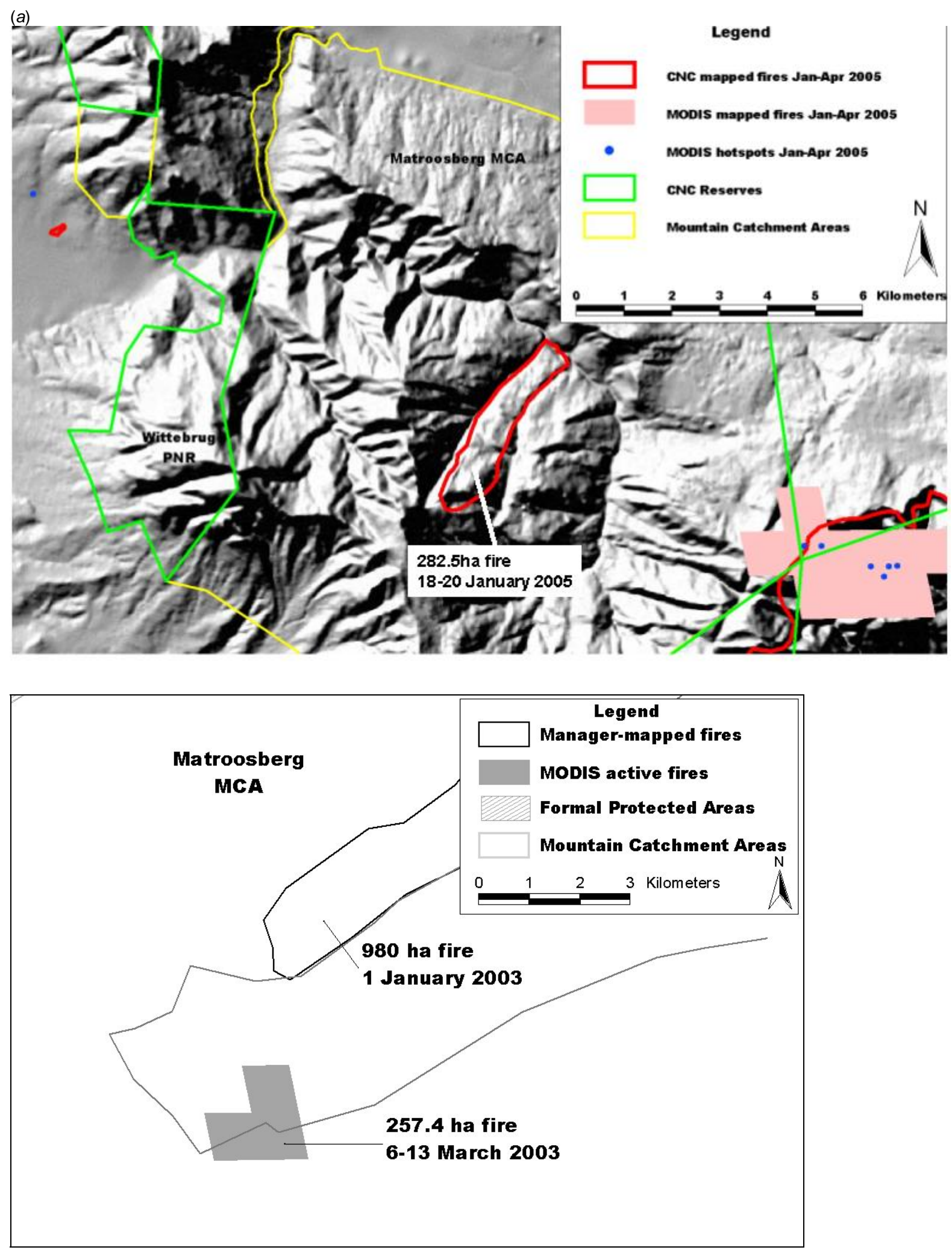

Fig. 2. Manager-mapped fires (black line) not mapped by theMODISactive fire product (solid grey) in the Matroosberg (a) between 18 and 20 January 2005, and (b) on 1 January 2003. 

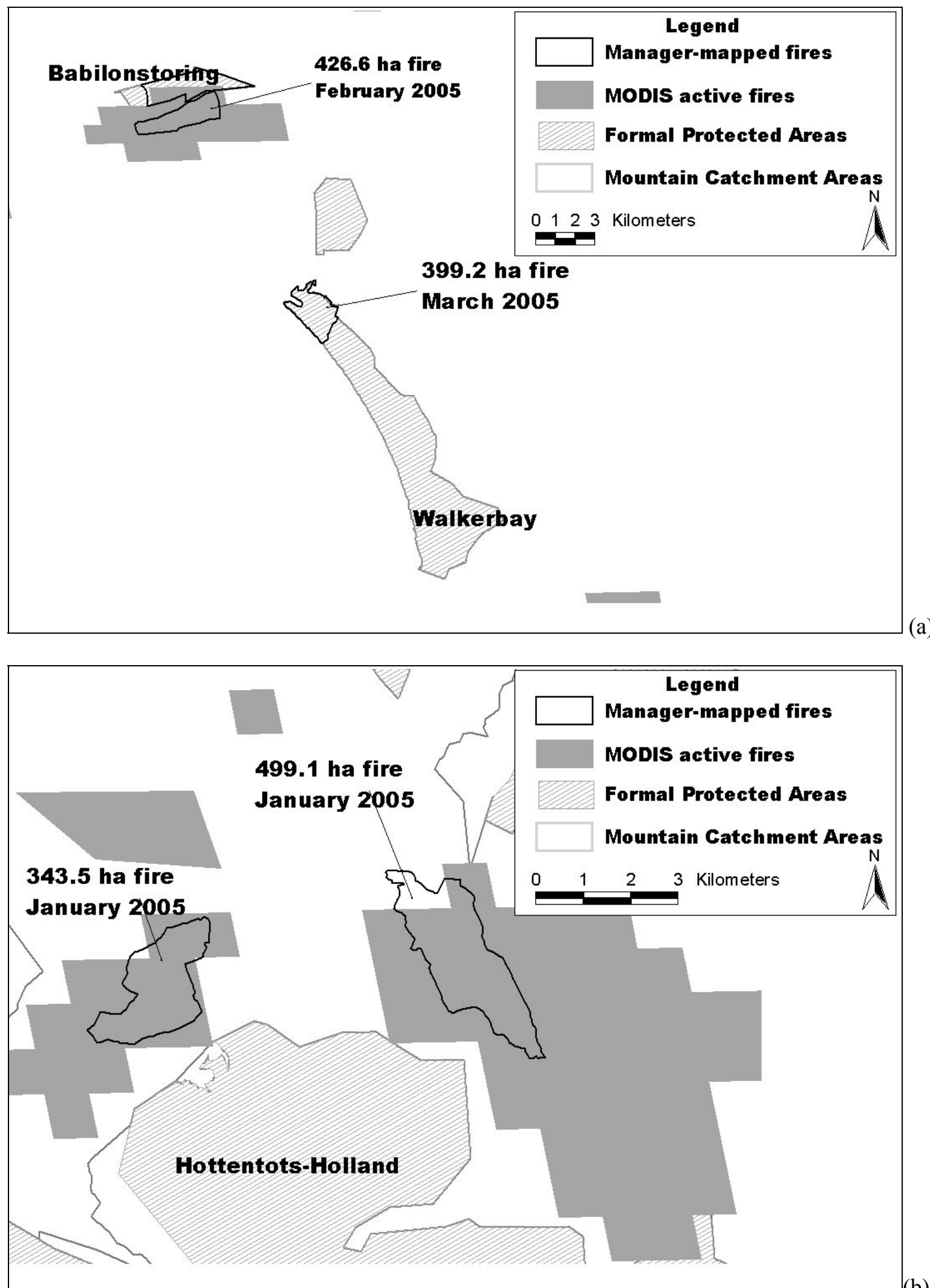


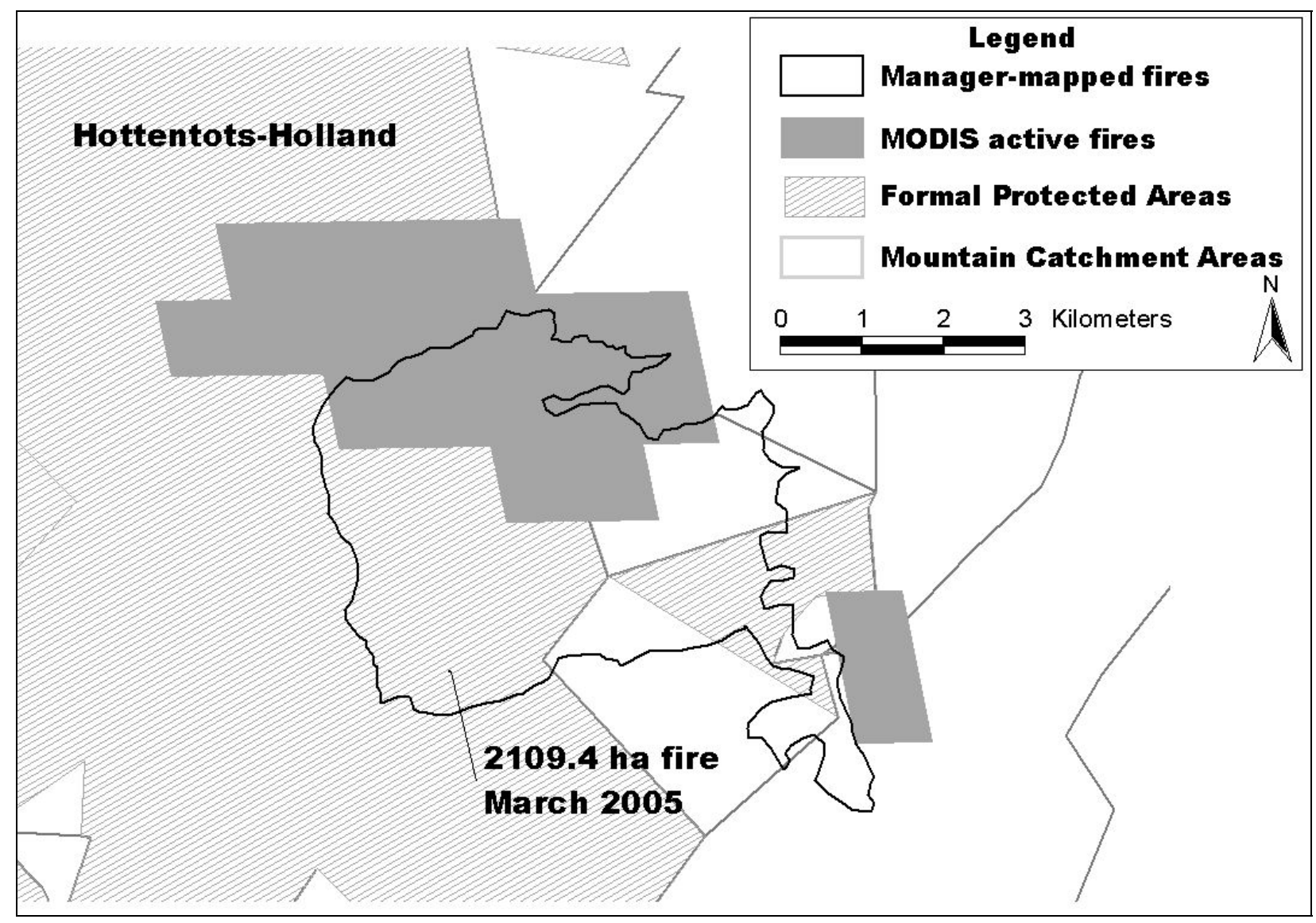

(c)

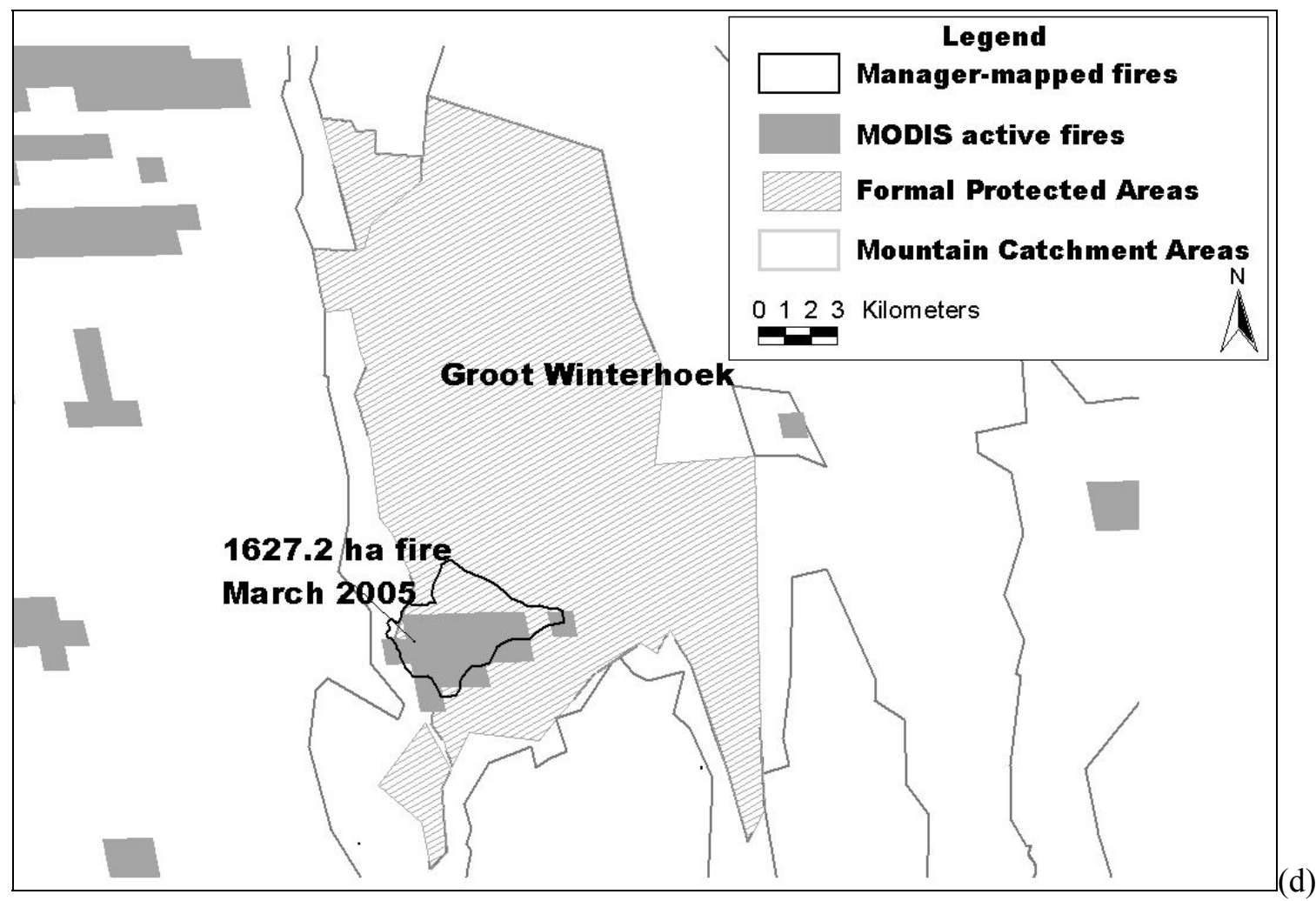




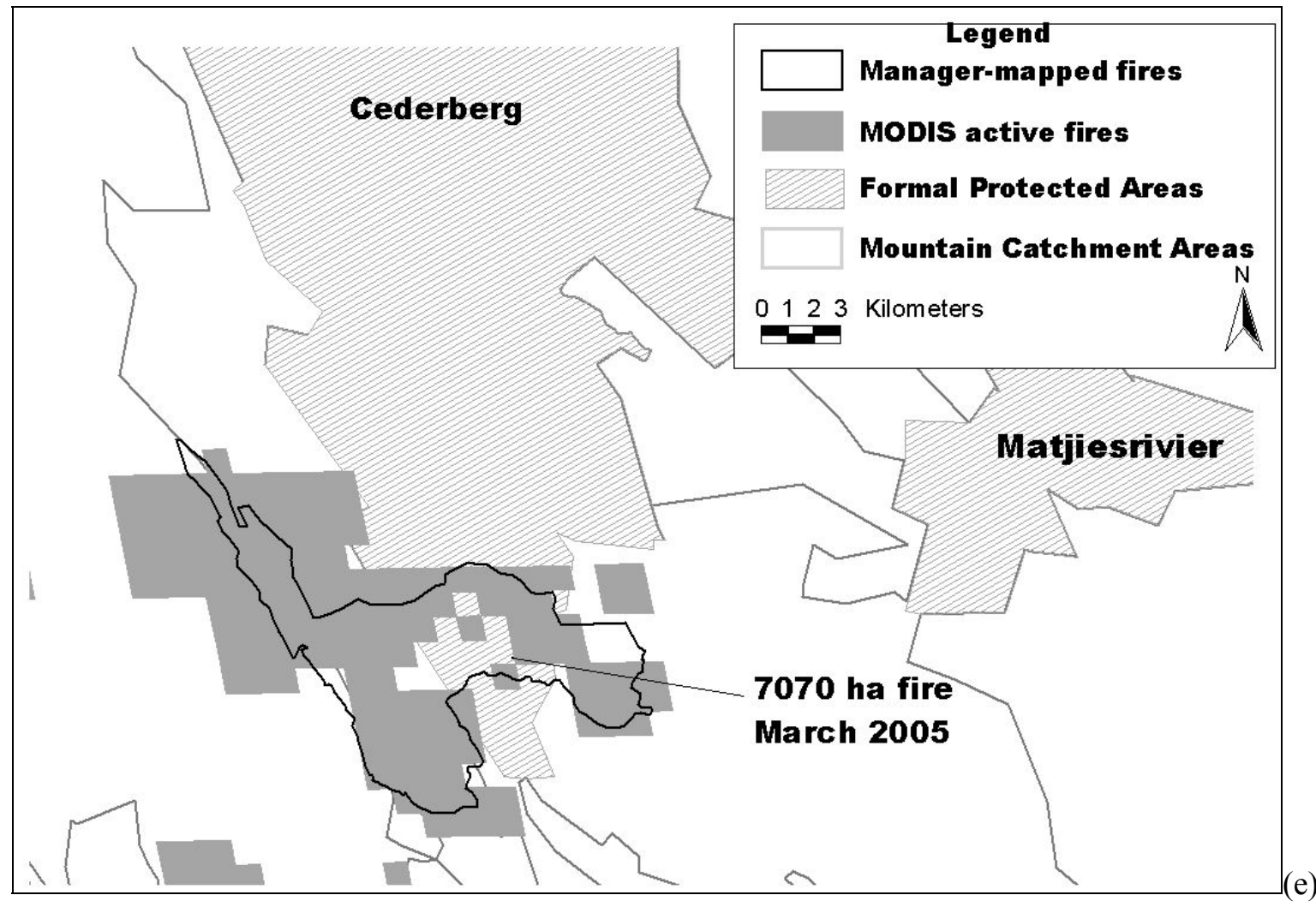

Fig. 3. Manager-mapped fires (black line) missed or partially mapped by the MODIS active fire product (solid grey) for (a)Walkerbay in March 2005 and Babilonstoring in February 2005; (b) Hottentots-Holland in January 2005; (c) Hottentots-Holland in March 2005; (d) GrootWinterhoek in March; and (e) the southern Cederberg in March 2005. Reserve boundaries are in green. 


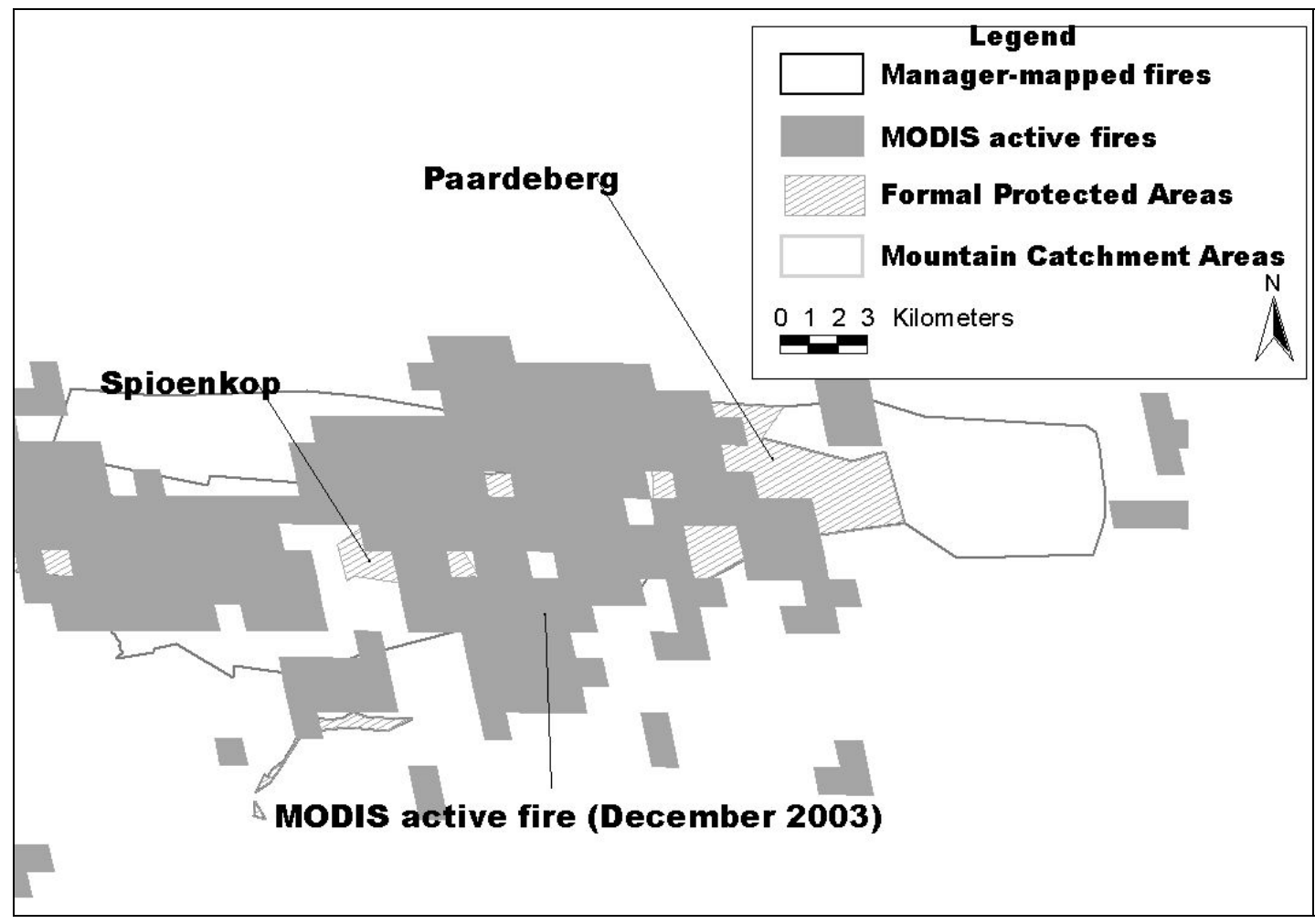

(a)

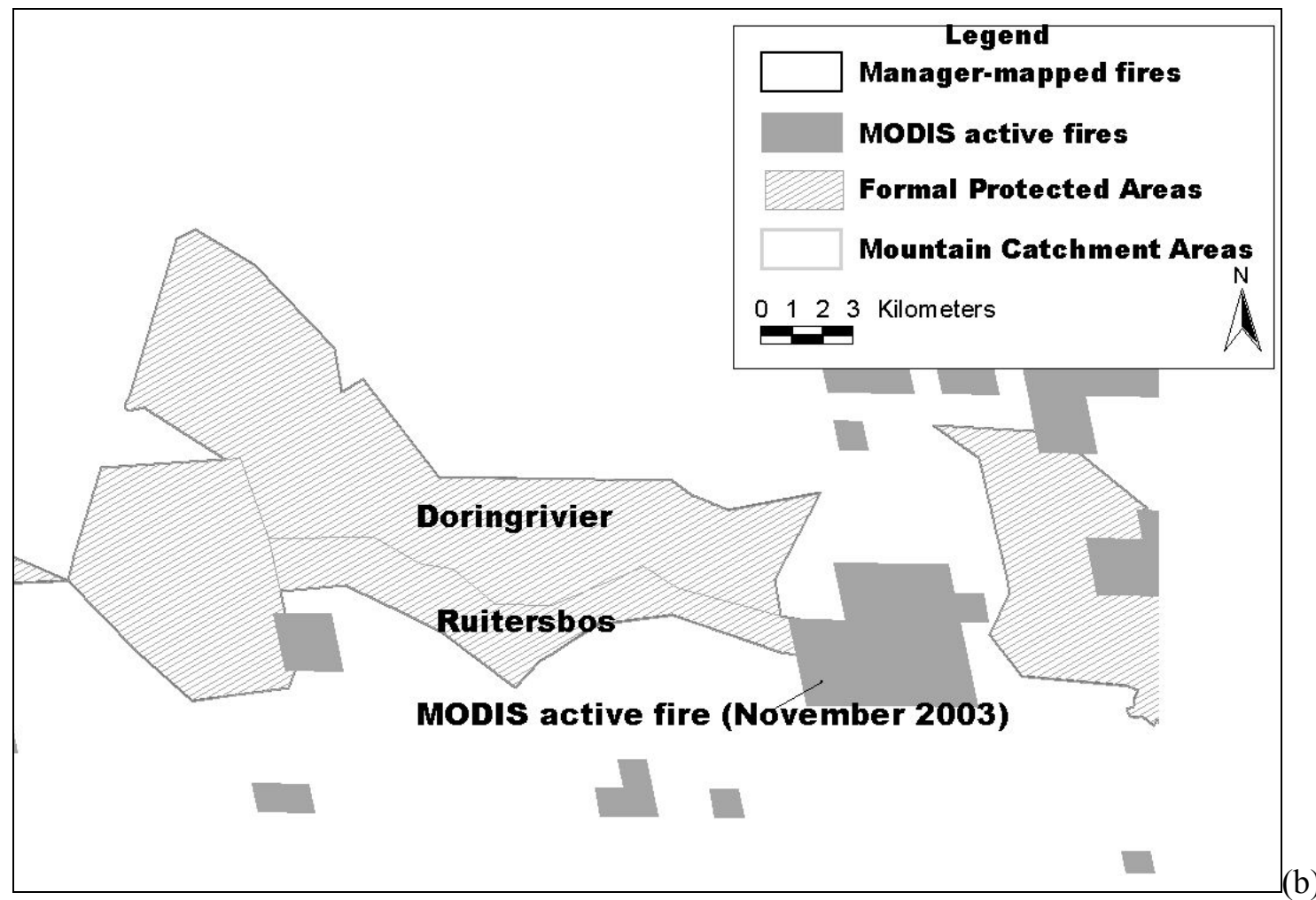

Fig. 4. MODIS active fires data (solid grey) in areas managed by the Western Cape Nature Conservation Board (WCNCB) not mapped by managers $(a)$ in Grootvadersbosch (Tygerberg, Paardeberg, and Spioenkop) in December 2003, and (b) in Ruitersbos-Doringrivier between 17 and 24 November 2003. 